\title{
HARTMANN, Peter Claus, REESE, Annette, Religion und Kultur im Europa des 17. und 18. Jahrhunderts
}

Philippe Büttgen

\section{OpenEdition}

\section{Journals}

Édition électronique

URL : http://journals.openedition.org/ifha/740

DOI : $10.4000 /$ ifha. 740

ISSN : 2198-8943

Éditeur

IFRA - Institut franco-allemand (sciences historiques et sociales)

Référence électronique

Philippe Büttgen, «HARTMANN, Peter Claus, REESE, Annette, Religion und Kultur im Europa des 17. und 18. Jahrhunderts », Revue de l'IFHA [En ligne], Date de recension, mis en ligne le 01 janvier 2006, consulté le 22 septembre 2020. URL : http://journals.openedition.org/ifha/740 ; DOI : https://doi.org/ 10.4000/ifha.740

Ce document a été généré automatiquement le 22 septembre 2020.

(C)IFHA 


\title{
HARTMANN, Peter Claus, REESE, Annette, Religion und Kultur im Europa des 17. und 18. Jahrhunderts
}

\author{
Philippe Büttgen
}

Le titre laissait croire à une actualité de ce volume : l'ouvrage quasi-homonyme de Kaspar von Greyerz (Religion und Kultur. Europa 1500-1800, Göttingen : Vandenhoeck \& Ruprecht, 2000, voir BullMHFA, 39, 2001, p. 399-400) et les discussions menées autour de la notion de «culture confessionnelle » (voir le prochain volume, encore à paraître, du Verein für Reformationsgeschichte sur Konfession und Kultur) ouvrent depuis peu la voie à une redéfinition des frontières disciplinaires, notamment entre histoire " générale " et histoire de l'Église, dans l'étude des cultures pré-modernes. L'avertissement n'en est que plus nécessaire : toute ressemblance serait purement fortuite. En lieu et place d'une discussion scientifique, les vingt-quatre communications de ce volume d'Actes de colloque offrent le spectacle délassant d'une conversation aimable entre savants cultivés. L'inspiration semble se trouver dans la Kulturgeschichte des Heiligen Römischen Reiches de P.C.H. (Wien/ Köln/ Graz : Böhlau, 2001, voir BullMHFA, 38, 2002, p. 342-343), abondamment citée à chaque fois que les contributeurs cherchent à se souvenir de quoi ils devaient parler. La précision des termes ne doit certes pas virer à la contrainte, et il n'est pas en soi révoltant de partir d'un « concept très large de culture, qui prend en vue tous les domaines de l'existence de l'homme " (P.C.H., p. 13). Il n'est pas scandaleux non plus de ne pas chercher à toutes les pages à préciser ce concept, pour finalement en arriver à la formule unique et ultime de la culture qui s'imposera au royaume de la théorie. Le problème est plutôt que tout semble joué d'avance, dans un montage d'oppositions automatiques entre « catholiques " et " protestants ", culture de l'image et culture de la parole, où toute distinction effective se mue en compromis de papier (par exemple, sur la question des images, la " position intermédiaire » [p. 17] des luthériens, entre les catholiques et les « calvinistes ", comme P.C.H. appelle les réformés). L'ouverture affichée à l'histoire culturelle des confessions non chrétiennes procède du même raisonnement bijectif : à chaque confession sa culture et sans doute inversement, « les juifs eux aussi ont développé leur 
propre culture, typique et autonome » (p. 14). Cette histoire culturelle ne cultive guère l'hybridation, et l'empirisme le plus courtois peut dissimuler de vraies raideurs de pensée : on le voit aussi à l'assaut énergiquement mené par l'éditeur du volume contre l'« approche unilatérale, étroite d'esprit » qui suggère à l'histoire culturelle d'aborder « sous de nouveaux points de vue les problématiques de l'histoire politique et sociale " (p. 13). Il est vrai que la dernière formule avait contre elle de provenir d'une recension mitigée de la Kulturgeschichte de P.C.H., mais la demande qui s'y exprime ne paraît pas exorbitante.

Le premier ensemble de contributions est consacré aux rapports entre culture et religion dans divers pays d'Europe. À l'exception d'A. SCHINDLING, qui résume efficacement sa recherche sur le lien entre confessions et territoires d'Empire, et de W. FRIJHOFF, qui développe une thèse personnelle et heureusement distanciée de l'irénisme habituel sur le lien entre pluralité confessionnelle et culture de la tolérance dans les Provinces-Unies, les textes, dans leur brièveté, n'atteignent pas le niveau de la vulgarisation réussie : il ne sera pas nécessaire de soupçonner un excès de subtilité théorique dans un intitulé du type " La culture catholique en Italie aux XVIIe et XVIIIe s. ". On trouvera en revanche des informations dans les articles traitant des productions culturelles : W. HOCHSTEIN tente une avancée vers une histoire sociale de la musique religieuse, S. KUMMER et J. HARASIMOWICZ livrent un savoir positiviste mais utile sur l'évolution des architectures ecclésiastiques. Les textes de W. NEUGEBAUER, K. AMANN et $\mathrm{H}$. SCHNABEL-SCHÜLE sur les systèmes éducatifs enrichissent et diversifient l'approche liminaire d'A. SCHINDLING, qui avait spontanément assimilé les « pays de culture " (Kulturlandschaften) qu'il étudiait à des « pays de culture et de formation " en centrant sa perspective sur l'histoire des universités. Les contributions finales sur les cultures populaires (W. HARTINGER, Ch. KÖHLE-HEZINGER, J. MEYER) sont laconiques.

De l'assemblage rhapsodique du recueil - les regroupements qui viennent d'être décrits ne correspondent à aucune forme de progression du propos -, deux constantes émergent : une méfiance spontanée, voire réflexe, envers le paradigme de la confessionnalisation (voir p. ex. p. 168), et une dilection pour la notion de "baroque " et de « culture baroque » (p. 212, 291), qui ne s'embarrasse pas de ce qu'a pu apporter la dénonciation du " mirage baroque " (Pierre Charpentrat) et des facilités de l'esthétisme. Au moins l'étude émergente des cultures confessionnelles pourra-t-elle identifier là deux écueils possibles, parmi d'autres.

Philippe BÜTTGEN (Centre National de la Recherche Scientifique/ MHFA) 